\title{
Turnover Intention and Perceived Organizational Support; Mediating Role of Work Engagement and Organizational Commitment
}

\author{
Kashif Nadeem \\ NUML University, Pakistan \\ Muhammad Ahsan Khan
}

Hailey College of Commerce, University of the Punjab, Lahore, Pakistan

Ms. Nazish Imtiaz.

Lahore Garrison University, Pakistan

Yasir Iftikhar

N.C.B.A\&E

Doi:10.19044/esj.2019.v15n10p222 URL:http://dx.doi.org/10.19044/esj.2019.v15n10p222

\begin{abstract}
The purpose of this research is to address practical issues regarding the prediction and prevention of turnover intentions of highly skilled employees by focusing on Perceived Organizational Support and two of its outcomes i.e. Organizational Commitment and Work Engagement. Data was collected from different banks of Lahore i.e; Bank of Punjab, Habib Bank Ltd., Meezan Bank, Alfalah Bank, Standard Chartered, UBL, and MCB were visited. This crosssectional study has used a quantitative technique in order to collect data from a sample size of 300 respondents. In this study, item response theory is used to select the sample size. To collect the data, the questionnaires were distributed among bankers. The response rate was $93 \%$ (i.e. 280 out of 300). Results show that Perceived Organizational support has a high impact on turnover intention whereas the organizational commitment and work engagement both can support the Perceived organizational support. Whereas if Perceived organizational support is increased with the help of Organizational Commitment and Work Engagement there will be less turn over intentions in the Organization.
\end{abstract}

Keywords: Perceived Organizational Support, Work Engagement, Organizational Commitment, Turnover Intention 


\section{Introduction}

Turnover intention (TOI), is referred to as "a deliberate and conscious willfulness to leave the organization within a foreseeable future" (Ertureten, 2013). It is highlighted by Shaw et al. (1998) that even after a century and completion of almost 1500 researches; the importance of this topic has not decreased. Having a strong Human resource is becoming inevitable for employers because of tough competitions (Islam et al., 2014). So this issue requires attention because of the high rate of TOI badly affect employees' commitment, unity, and communication structure of the organization (Staw, 1980). An organization must investigate those factors which negatively influence employee's performance and promote TOI as they are the most important determinants of employees' behavior (Van Schalkwyk, Bothma, DuToit \& Rothmann, 2010). A number of solutions have been provided by researchers in order to decrease TOI (Imran, Ali, \& Islam, 2014). So the goal of this study is to address concerns regarding the prediction and prevention of high TOI.

Few studies suggest that by enhancing organizational support; TOI can be reduced (Islam et al., 2014). Perceived organizational support (POS) is defined by Eisenberger et al. (1986) as "beliefs concerning the extent to which the organization values their contribution and cares about their well-being". Researchers claim that employees expect from their organization that it will fulfill their socio-emotional requirements, which afterward indebts workers to return them favorably (Avanzi et al., 2014). It is narrated by Rhoades and Eisenberge (2002) that basic concept of POS is derived from Exchange theories ("Organizational support theory and social exchange theory"), which consider that employees provided positive outcomes like organizational commitment, work engagement, job satisfaction and reduced TOI when they find POS from their organization (Blau,1964).

Many researchers found that POS causes outcomes, e.g. work engagement (Alfes et al., 2013), organizational commitment (Celep \& Yilmazturk, 2012) and TOI (Avanzi et al., 2014) while this study aims to examine three outcomes of POS, i.e. organizational commitment, work engagement, and turnover intention. Organizational commitment (OC) is explained as, "an employee's attitude or a binding force that keep him devoted to continuing his services for the organization" (Gallie, Felstead \& Green, 2001). A study conducted by Allen and Meyer in 1991 concluded that OC has great importance because it directly affects the performance of employees, they further categorized $\mathrm{OC}$ in three categories, i.e. effective, continuance and normative commitment which were further assessed by other researchers in their framework. Affective commitment is about employees' emotional involvement with their organization so they "want to" stay. Continuance commitment is related to the "need" to remain committed because the leaving 
cost is higher while normative commitment makes employees feel that they "ought to" stay because it is their obligation. Carmeli \& Weisberg (2006) highlighted that OC is the most important determinant of TOI and many other studies also revealed that due to lack of OC, TOI increase.

Carmeli and Weisberg (2006) also suggested that motivational factors should be analyzed to reduce TOI among employees for this purpose, work engagement is also considered to be a predictor of TOI (Steel \& Ovalle, 1984). Work Engagement (WE) can be explained as "a positive, fulfilling, work-related state of mind that is characterized by vigor, dedication, and absorption" (Schaufeli \& Bakker, 2010). Vigor involves willingness, a higher level of motivation and persistence. Dedication is about enthusiasm, challenge, and pride while absorption means full concentration and dedication in such a way that separation can cause troubles. WE have been studied many times as a mediator which links HRM antecedents and its outcomes (Muduli et al., 2016), as measuring WE is not enough so the causes and effects of WE should also be investigated (Mann \& Harter, 2016).

Due to having different cultures and economies, work characteristics like job satisfaction (JS), work engagement (WE), organizational commitment (OC) and turnover intentions (TOI) vary among countries. In the context of Pakistan, Imran et al. (2014) investigated that TO is becoming problematic, especially for its Banking Sector as State bank of Pakistan's report (2012 13) claims that $24 \%$ employees leave the job on an annual basis (Islam et al., 2014). Therefore, recruitment of new employees due to high TO costs the organization ten times higher as compared to retaining the current employees (Robbins \& Judge, 2005).

There are various factors that influence employees' turnover. But this research does not cover all those factors rather itcontributes to the current research by investigating the association of TOI with those factors. Hence, this research aims to focus on four concepts i.e. Perceived Organizational support, Work engagement, Organizational Commitment, and Turnover Intention.

\section{Literature Review RELATIONSHIP BETWEEN TOI AND POS}

Islam et al. (2014) claim that many researchers have worked on employees and employers' exchange relationships, according to which employees outcomes depend upon their perception about the organization (Avanzi et al., 2014). Foundation of POS was drawn from "Theory of Social exchange" by Blau (1964) which narrates that positive outcomes e.g. turnover intention can easily be reduced by focusing on POS. It also includes that employees, who find their organization, supportive, try to reciprocate those efforts through their positive behaviors (Eisenberger et al., 1986) like 
decreased withdrawal behaviors, lesser deviance, improved performance and displaying higher affective commitment (Rhoades et al., 2001). Therefore, lesser TOI has been observed among employees who are satisfied with their organization.

Shaw et al. (2005) found that TO is harmful as it doesn't only affect economic position but also causes loss of investment by losing experienced and skilled workers and decreases productivity by discouraging and demotivating remaining employees (Lee \& Shin, 2005). In order to avoid these adverse effects on organizational effectiveness, a manager needs to understand the various determinants, for example, a study conducted by Islam et al. (2013) proved that a decrease in organizational commitment and other variables, cause higher TO which becomes challenging for managers. Therefore, his study emphasizes on the negative association between TO and POS.

H1: There exists a negative relationship between Perceived organizational support and Turnover Intention

\section{RELATIONSHIP BETWEEN POS AND WE}

POS is examined by researchers through many relationships including employer-employee relationship which infers that there is a positive association between WE and POS (Eisenberger et al., 1986). Individuals having high support from their organization tend to provide better outcomes that eventually lead to a positive relationship with coworkers and better outcomes (Muduli et al., 2016). These employees remain engaged with their work and their intentions to leave the organization, are reduced hence WE act as a mediator (Mann \& Harter, 2016).

H2: There exists a negative relationship between Perceived organizational support and Work Engagement

\section{RELATIONSHIP BETWEEN WE AND TOI}

Many researchers reveal that the organizations that provide availability of resources, job enrichment, work-role fit, supportive co-workers and managers tend to have highly engaged workers (Mann and Harter, 2016). "Employees with a high level of engagement are five times less likely to voluntarily leave the Organization" (Vance 2006). Schaufeli \& Bakker also conducted a survey in 2004 and proved that WE and TO are negatively related with each other, they also found that high level of WE positively affects the intent to stay with the organization which also implies that low WE cause high TO (Schaufeli \& Bakker, 2010).

H3: There exists a negative relationship between Work Engagement and Turnover Intention 


\section{MEDIATING ROLE OF WORK ENGAGEMENT BETWEEN TOI AND POS}

A significant number of research studies by Schaufeli have claimed that WE work as a mediator in HRM-turnover models. Even after its huge importance as a mediator, its role between POS and TOI is scarcely observed so this study will contribute to this perspective.

H4: Work engagement mediates the relationship between Perceived organizational support and Turnover Intention

\section{RELATIONSHIP BETWEEN POS AND OC}

When employees find POS within their organization, they tend to depict higher organizational commitment (Celep \& Yilmazturk, 2012) which eventually yields reduced turnover intentions (Avanzi et al., 2014). It is considered on the basis of Exchange theories that POS causes higher commitment in employees (Celep \& Yilmazturk, 2012), through which, TOI is also discouraged. So the relationships between POS, OC, and TO can be described as follow,

H5: There exists a Positive relationship between Perceived organizational support and Organizational commitment

\section{RELATIONSHIP BETWEEN OC AND TOI}

Employees' commitment has been investigated in different ways. According to the Journal of Management Development, "It is generally assumed that committed employees are more prepared to achieve organizational goals than non-committed employees". A lot of studies have been conducted by Meyer and Allen (1991) and many other researchers, to understand the association between OC and TOI which proves that OC positively influences employees' performance such as, it lowers absenteeism, improves effectiveness and hence decreases TOI (Meyer, Stanley, Herscovitch \& Topolnytsky, 2002). Many researchers including Steel and Ovalle (1984) investigated that there was a negative association between OC and TOI while Bluedorn's (1982) in his 23 studies proved that TOI predicts actual TO. Hence, there are many studies that prove the negative relationship between $\mathrm{OC}$ and TO.

H6: There exists a negative relationship between Organizational Commitment and Turnover Intention

\section{MEDIATING ROLE OF ORGANIZATIONAL COMMITMENT BETWEEN TOI AND POS}

When employees are provided with POS from their organization, they become highly committed with the organization especially in the form of affective commitment (Islam et al., 2014, Ahmed et al., 2014). The 
researchers have proved that $\mathrm{OC}$ is essential in order to reduce TO (Islam $e t$ al., 2013). So this study aims to investigate the influence of POS in the reduction of TOI among the employees or Pakistan's banking sector.

H7: Organizational Commitment mediates the relationship between Perceived organizational support and Turnover Intention.

The objectives of this research study are to address practical issues regarding the prediction and prevention of turnover intentions of highly skilled employees by focusing on POS and two of its outcomes i.e. OC and WE. This study also contributes to previous literature about employees' work engagement and Organizational Commitment which eventually prove beneficial for a reduction in the intentions of employees to leave the organization.

\section{Theoretical Framework}

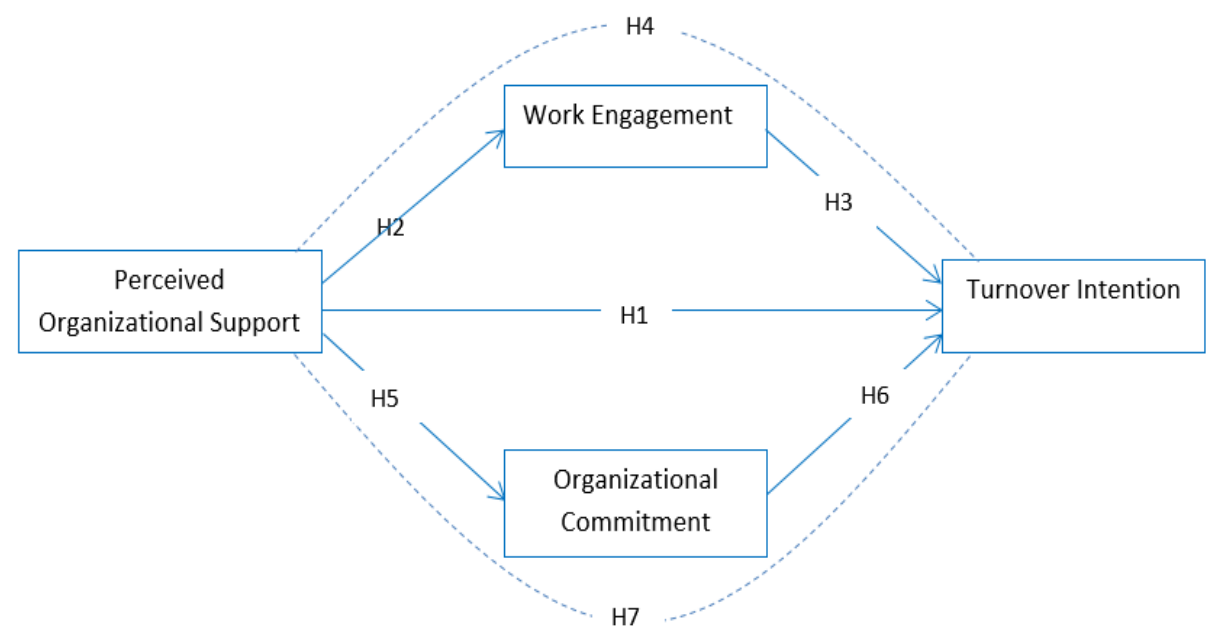

\section{Hypothesis}

H1: There exists a negative relationship between Perceived organizational support and Turnover Intention

H2: There exists a relationship between Perceived organizational support and Work Engagement

H3: There exists a negative relationship between Work Engagement and Turnover Intention

H4: Work engagement mediates the relationship between Perceived organizational support and Turnover Intention

H5: There exists a Positive relationship between Perceived organizational support and Organizational commitment

H6: There exists a negative relationship between Organizational Commitment and Turnover Intention 
H7: Organizational Commitment mediates the relationship between Perceived organizational support and Turnover Intention.

\section{Methodology}

This research study targets the employees of the Pakistani Banking sector for conducting the research. According to the State Bank of Pakistan, there are total 22 private and public banks, operating throughout the country. After 2007 financial crises banks of Pakistan have started to compete with each other (Islam, 2014). Due to which, all banks have started attracting skilled and potential candidates from each other that promote turnover intentions in the banking sector. For survey purposes, Bank of Punjab, Habib Bank Ltd., Meezan Bank, Alfalah Bank, Standard Chartered, UBL, and MCB were visited. This cross-sectional study has used a qualitative technique in order to collect data from a sample size of 300 bankers. It is using item response theory in which thumb rule was followed and the sample size was determined by multiplying a number of questions with 10 . By using a convenience sampling technique, the respondents were approached personally by visiting banks. Managers were asked for permission to conduct a survey and questionnaires were distributed among bankers. The response rate was 93\% (i.e. 280 out of 300). The questionnaire was divided into two parts, the first part requires personal information like gender, age etc. whereas the second part consisted of questions related to the variables like Perceived organizational support, Organizational Commitment, Work Engagement, and Turnover Intentions.

\section{Instrumentation}

Respondents were assessed on the basis of five points Likert Scale which ranges from $1=$ Strongly Disagree to $5=$ strongly agree. In order to measure POS, an 8-item scale by Eisenberg et al. (1986), which was reduced to 6-item scale is used and its reliability is reposted as 0.76 by Islam et al. (2015). A sample operationalized statement for POS includes, "My organization really cares about my well-being."

TOI was measured using a 3-item scale developed by Lichtenstein et al. (2004) and its reliability is reported as 0.83 . The sample includes, "I often think about quitting this job."

Allen and Meyer (1990) introduced a 16-item scale to measure OC that was further reduced to 6-item scale by Gellately, Meter and Luchak (2006). The same scale is used in this study in which each dimension contains 3 items and reported its reliability higher than the previous scale. Its sample statement includes, "I really feel as if this organization's problems are my own."

WE are measured by using a 9-item Utrecht Work Engagement Scale (UWES) developed by Schaufeli et al. (2006) and there is a high correlation 
among its three determinants i.e. dedication, vigor, and absorption. A sample item includes, "At my work, I feel I am bursting with energy".

Analysis:

Correlation:

\begin{tabular}{ccccccc}
\hline & Mean & $\begin{array}{c}\text { St. } \\
\text { Deviation }\end{array}$ & 1 & 2 & 3 & 4 \\
\hline POS & 3.7479 & .88687 & 0.76 \\
WE & 3.6707 & .58424 & $.435^{* *}$ & 0.77 & & \\
OC & 3.7115 & .66728 & $.411^{* *}$ & $.522^{* *}$ & 0.75 & \\
TOI & 3.8182 & .89201 & $.311^{* *}$ & $.404^{* *}$ & $.561^{* *}$ & 0.83 \\
\multicolumn{7}{c}{$* *$ Correlation is significant at the 0.01 level (2-tailed). } \\
\hline
\end{tabular}

Above table shows the relationships among variables. All values are less than .9 which shows there is no issue of multicollinearity in the data. It also shows the mean values with a minimum range of 2.2 to a maximum range of 3.8. And also shows the value of standard deviation with a minimum value of .584 to maximum value .892 .

Reliability of each variable is also shown diagonally.

\section{Confirmatory Factor Analysis:}

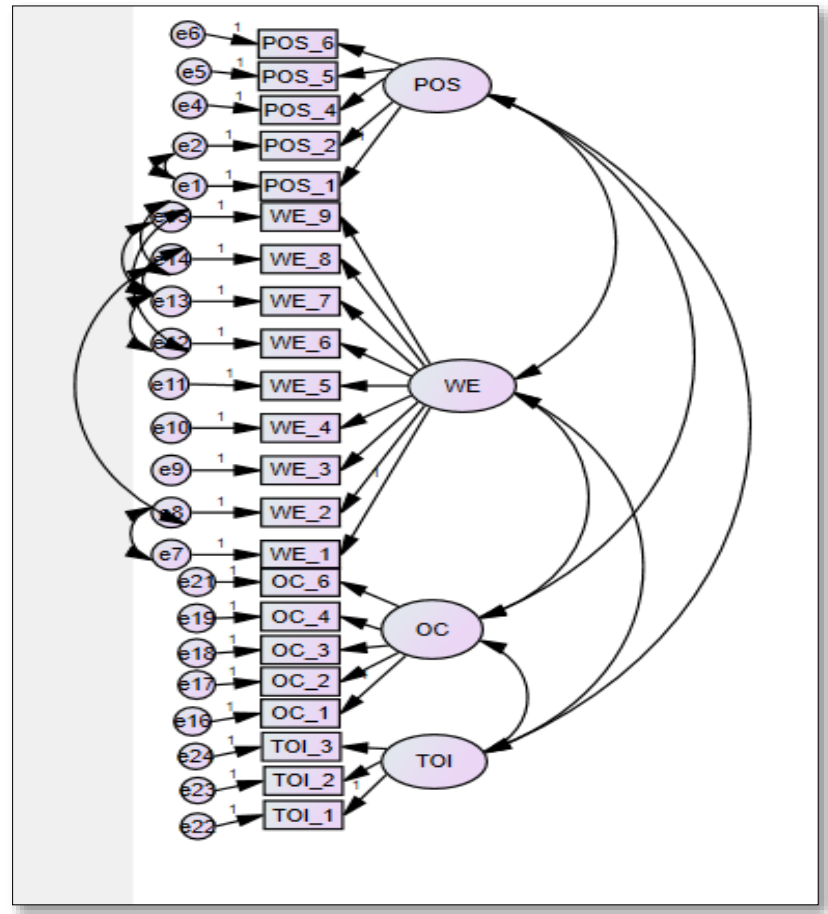

Figure 1: Measurement Model Standardized Regression Weights: (Group number 1 Default model) 


\begin{tabular}{|lll|l|}
\hline POS_1 & $<---$ & POS & .717 \\
POS_2 & $<---$ & POS & .765 \\
POS_4 & $<---$ & POS & .716 \\
POS_5 & $<---$ & POS & .725 \\
POS_6 & $<---$ & POS & .584 \\
WE_1 & $<---$ & WE & .597 \\
WE_2 & $<---$ & WE & .634 \\
WE_3 & $<---$ & WE & .543 \\
WE_4 & $<---$ & WE & .598 \\
WE_5 & $<---$ & WE & .562 \\
WE_6 & $<---$ & WE & .356 \\
WE_7 & $<---$ & WE & .365 \\
WE_8 & $<---$ & WE & .389 \\
WE_9 & $<---$ & WE & .384 \\
OC_1 & $<---$ & OC & .751 \\
OC_2 & $<---$ & OC & .786 \\
OC_3 & $<---$ & OC & .724 \\
OC_4 & $<---$ & OC & .682 \\
OC_6 & $<---$ & OC & .385 \\
TOI_1 $<---$ & TOI & .804 \\
TOI_2 & $<---$ & TOI & .809 \\
TOI_3 & $<---$ & TOI & .707 \\
\hline
\end{tabular}

All the values of the above table are greater than 3 which is acceptable.

Fitness summary:

\begin{tabular}{|c|c|c|c|c|c|}
\hline CMIN/DF & CFI & GFI & AGFI & RMSEA & PCLOSE \\
\hline 1.650 & .943 & .901 & .872 & .049 & .577 \\
\hline
\end{tabular}

According to $\mathrm{Hu}$ and Bentler, (1999) argued that the value of CFI is considered good if the value of CFI is greater than .9. The value of GFI should be greater than .9. The value of AGFI is considered good if the value of AGFI is greater than .85. And the value of RMSEA should be less than .08 which considered overall model is a good fit. 


\section{Structural Equational Model:}

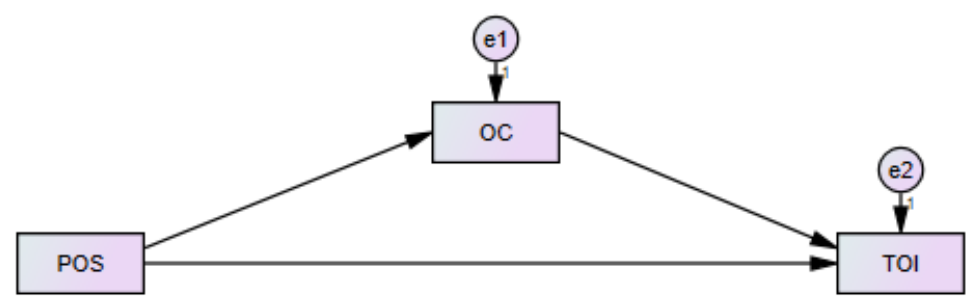

Figure 2: Structural Equational Model

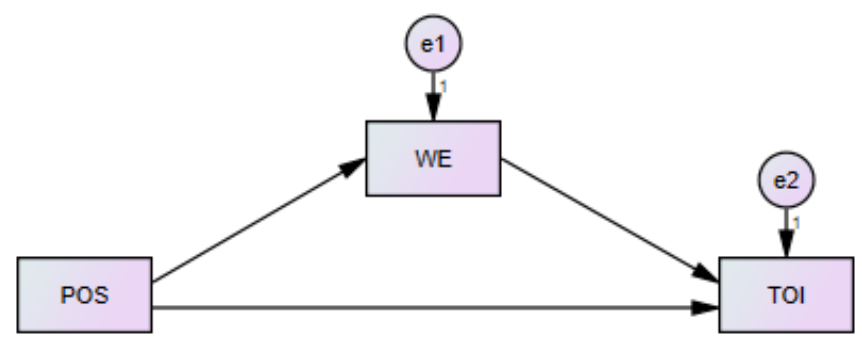

Regression Weights: (Group number 1 - Default model)

\begin{tabular}{|cc|rc|}
\hline & & Estimate & P \\
\hline OC $<---$ & POS & .669 & $* * *$ \\
TOI $<---$ & OC & .637 & $* * *$ \\
TOI <--- & POS & .110 & .089 \\
\hline
\end{tabular}

Regression Weights: (Group number 2 - Default model)

\begin{tabular}{|cc|rc|}
\hline & & Estimate & P \\
\hline WE $<---$ & POS & .555 & $* * *$ \\
TOI <--- & POS & .164 & .030 \\
TOI <--- & WE & .670 & $* * *$ \\
\hline
\end{tabular}

\section{Bootstrapping Strategy:}

For mediation analysis, the bootstrapping strategy is used to examine both direct and indirect effects of the model. 
Mediation Analysis:

\begin{tabular}{|c|c|c|c|c|}
\hline Paths & $\begin{array}{c}\text { Direct Beta } \\
\text { Without Mediation }\end{array}$ & $\begin{array}{c}\text { Direct Beta } \\
\text { With Mediation }\end{array}$ & Indirect Beta & Results \\
\hline POS- $\rightarrow$ OC-- $\rightarrow$ TOI & $.110^{* *}$ & $.110^{* *}$ & $.427^{* *}$ & Partial \\
\hline POS-- $\rightarrow$ WE- $\rightarrow$ TOI & $.164^{* *}$ & $.164^{* *}$ & $.373^{* *}$ & Partial \\
\hline
\end{tabular}

\section{Discussion:}

\section{There are some hypotheses of this study which is as follows:}

HI shows that there is a significant positive relationship among POS and TOI, because according to which employees outcomes depend upon their perception about the organization (Avanzi et al., 2014). A study conducted by Islam et al. (2013) proved that a decrease in organizational commitment and other variables, cause higher TO which becomes challenging for managers. Therefore, his study emphasizes on the negative association between TO and POS. H2 supported a significant positive relationship among perceived organizational support and work engagement. In different previous studies employer-employee relationship which infers that there is a positive association between WE and POS (Eisenberger et al., 1986). Individuals having high support from their organization tend to provide better outcomes that eventually lead to a positive relationship with coworkers and better outcomes (Muduli et al., 2016). H3 also shows a significant positive relationship between WE and TOI. In previous studies Schaufeli \& Bakker also conducted a survey in 2004 and proved that WE and TO are negatively related with each other, they also found that high level of WE positively affects the intent to stay with the organization which also implies that low WE cause high TOI (Schaufeli \& Bakker, 2010). H4 shows that Work engagement positively significantly mediates the relationship between Perceived organizational support and Turnover intention whereas in some previous one by Schaufeli have claimed that WE work as a mediator in HRM-turnover models. H5 shows a significant positive relationship among POS and OS, similarly in previous studies When employees find POS within their organization, they tend to depict higher organizational commitment (Celep \& Yilmazturk, 2012) which eventually yields reduced turnover intentions (Avanzi et al., 2014). It is considered on the basis of Exchange theories that POS causes higher commitment in employees (Celep \& Yilmazturk, 2012), through which, TOI is also discouraged. H6 also shows a significant positive relationship between OS and TOI but in some previous studies like Meyer and Allen (1991) and many other researchers, to understand the association between OC and TOI which proves that, OC positively influences employees' performance such as, it lowers absenteeism, improves effectiveness and hence decreases TOI (Meyer, Stanley, Herscovitch \& Topolnytsky, 2002). H7 supported that Organizational Commitment has significantly mediated the positive relationship between Perceived organizational support and Turnover 
Intention. Same as in previous studies When employees are provided with POS from their organization, they become highly committed with the organization especially in the form of affective commitment (Islam et al., 2014, Ahmed et al., 2014).

\section{Limitations:}

The study's scope was limited to a few Pakistani banks only. The study's findings might have been different if a larger sample of banks was included.

Since the study was limited only to the banking industry, the findings may be unique to this particular industry due to factors such as specific cond itions of employment and skills of the employee.

This aspect should be taken into account when generalizing the findin gs in future research.

Another limitation could be that respondents to the survey could have provided socially desirable responses as the study was done using self - repo rted questionnaires.Zerbe and Paulhus (1987) pointed out that Socially Desir able Response (SDR) refers to presenting oneself in favor of current social $n$ orms and standards.

\section{Conclusion:}

Perceived Organizational support has a high impact on turnover intention whereas the organizational commitment and work engagement both can support the POS. Whereas if POS is increased with the help of OC and WE so there is less turn over intention in the Organization and employees can do work better. When employees are provided with POS from their organization, they become highly committed with the organization especially in the form of affective commitment. There are various factors that influence employees' turnover. But this research does not cover all those factors rather it contributes to the current research by investigating the association of TOI with those factors. Hence, this research aims to focus on four concepts i.e. Perceived Organizational support, Work engagement, Organizational Commitment and Turnover Intention.

\section{References:}

1. Alfes, K., Shantz, A. D., Truss, C., \& Soane, E. C. (2013). The link between perceived human resource management practices, engagement and employee behavior: a moderated mediation model. The international journal of human resource management, 24(2), 330-351.

2. Avanzi, L., Fraccaroli, F., Sarchielli, G., Ullrich, J., \& van Dick, R. (2014). Staying or leaving: A combined social identity and social 
exchange approach to predicting employee turnover intentions. International Journal of Productivity and Performance Management, 63(3), 272-289.

3. Blau, H. (1964). The Impossible Theater: A Manifesto. Macmillan.

4. Bluedorn, A. C. (1982). The theories of turnover: Causes, effects, and meaning. Research in the Sociology of Organizations, 1(1), 75-128.

5. Carmeli, A., \& Weisberg, J. (2006). Exploring turnover intentions among three professional groups of employees. Human Resource Development International, 9(2), 191-206.

6. Celep, C., \& Yilmazturk, O. E. (2012). The relationship among organizational trust, multidimensional organizational commitment and perceived organizational support in educational organizations. Procedia-Social and Behavioral Sciences, 46, 57635776.

7. Shaw, J. D., Delery, J. E., Jenkins Jr, G. D., \& Gupta, N. (1998). An organization-level analysis of voluntary and involuntary turnover. Academy of management journal,41(5), 511525.Eisenberger, R., Huntington, R., Hutchison, S., \& Sowa, D. (1986). Perceived organizational support. Journal of Applied psychology, 71(3), 500.

8. Ertureten, A., Cemalcilar, Z., \& Aycan, Z. (2013). The relationship of downward mobbing with leadership style and organizational attitudes. Journal of Business Ethics, 116(1), 205-216.

9. Gallie, D., Felstead, A., \& Green, F. (2001). Employer policies and organizational commitment in Britain 1992-97. Journal of Management Studies, 38(8), 1081-1101.

10. Imran, M., Ali, G., \& Islam, T. (2014). The relationship between perceived organizational support and turnover intention: mediating role of affective commitment and job satisfaction. Research Journal of Applied Sciences, Engineering and Technology, 8(24), 2422-2425.

11. Islam, T., S.U.R. Khan, U.N.U. Ahmad, G. Ali, I. Ahmed and Z.A. Bowra, 2013. Turnover intentions: The role of perceived organizational support and organizational commitment. Proc. Soc. Behav. Sci., 103: 1237-1241.

12. Islam, T., Ahmad, U. N. U., \& Ahmed, I. (2014). Exploring the relationship between POS, OLC, job satisfaction and OCB. ProcediaSocial and Behavioral Sciences, 114, 164-169.

13. Lee, K. E., \& Shin, K. H. (2005). Job burnout, engagement and turnover intention of dietitians and chefs at a contract foodservice management company. Journal of Community Nutrition, 7(2), 100106. 
14. Mann, A., \& Harter, J. (2016). The worldwide employee engagement crisis. Gallup Business Journal, 7.

15. Meyer, J. P., \& Allen, N. J. (1991). Development of organisational commitment during the first year of employment: A longitudinal study of pre- and post-entry influences. Journal of Management, 17 (4), 717 733.

16. Meyer, J. P., Stanley, D. J., Herscovitch, L., \& Topolnytsky, L. (2002). Affective, continuance, and normative commitment to the organization: A meta-analysis of antecedents, correlates, and consequences. Journal of vocational behavior, 61(1), 20-52.

17. Muduli, A., Verma, S., \& Datta, S. K. (2016). High performance work system in India: Examining the role of employee engagement. Journal of Asia-Pacific Business, 17(2), 130-150.

18. Price, J. L. (2001). Reflections on the determinants of voluntary turnover. International Journal of Manpower, 22(7), 600-624.

19. Rhoades, L., Eisenberger, R., \& Armeli, S. (2001). Affective commitment to the organization: The contribution of perceived organizational support. Journal of applied psychology, 86(5), 825.

20. Robbins, S. P., Judge, T. A., \& Sanghi, S. (2005). Organizational behavior 11th Edition.

21. Schaufeli, W. B., \& Bakker, A. B. (2010). Defining and measuring work engagement: Bringing clarity to the concept. Work engagement: A handbook of essential theory and research, 10-24.

22. Shaw, J. D., Gupta, N., \& Delery, J. E. (2005). Alternative conceptualizations of the relationship between voluntary turnover and organizational performance. Academy of management journal, 48(1), 50-68.

23. Staw, B. M. (1980). The consequences of turnover. Journal of Occupational Behaviour, 253-273.

24. Steel, R. P., \& Ovalle, N. K. (1984). A review and meta-analysis of research on the relationship between behavioral intentions and employee turnover. Journal of applied psychology, 69(4), 673.

25. Van Schalkwyk, S., Du Toit, D. H., Bothma, A. S., \& Rothmann, S. (2010). Job insecurity, leadership empowerment behavior, employee engagement and intention to leave in a petrochemical laboratory. $S A$ Journal of Human Resource Management, 8(1), 7.

26. Vance, R. J. (2006). Employee engagement and commitment: A guide to understanding, measuring and increasing engagement in your organization. SHRM Foundation.

27. Ahmad, M. B., Ali, H. F., Malik, M. S., Humayun, A. A., \& Ahmad, S. (2019). Factors Affecting Impulsive Buying Behavior with the 
mediating role of Positive Mood: An Empirical Study. European Online Journal of Natural and Social Sciences, 8(1), pp-17.

28. Syed, Aleena., Ahmad, M. B., Ali, H. F., Arif, M.M., \& Gohar, A. (2018). Work-Family Conflict and Turnover Intentions: Moderated Mediation Model. Macro think Institute Online Journals, Human Resource Research, 2, 95-106

29. Danish, R.Q., Qazi, Ali., Mahmood, T., Qaseem, S., Ali, H. F., \& Ahmad, M. B (2019). Impact of Perceived Organizational Politics on Employee's Performance through Emotional Intelligence: Moderating Role of Political Skills. Journal of Harmonized Research in Management, 4,136-148.

30. Danish, R. Q., Shahid, R., \& Ali, H. F. (2019). Factors Affecting life Satisfaction of Employees under Financial Threat. SEISENSE Journal of Management, 2(1), 85-98.

31. Qaiser Danish, R., Ali, N., Fawad Ali, H., Afzal Humayon, A., Bilal Ahmad, M., \& Gohar, A. (2019). Spirit and Innovation at Work in Software Houses of Pakistan: How Does Job Satisfaction Intervene the Relationship?. European Online Journal of Natural and Social Sciences: Proceedings, 8(1 (s)), pp-66.

32. Danish, R. Q., Qaseem, S., Mehmood, T., Ali, Q. M., Ali, H. F., \& Shahid, R., (2019). Work-Related Stressors and Teachers' Performance: Evidence from College Teachers Working in Punjab. European Scientific Journal ESJ. 15. 158-173. 10.19044/esj.2019.v15n4p158. 